\title{
Helicobacter pylori infection and serum magnesium in kidney disease; current concepts
}

\author{
Banafsheh Yalameha ${ }^{1}{ }^{\circledR}$, Parto Nasri $^{2^{*}}$ \\ ${ }^{1}$ Department of Biochemistry, Faculty of Medicine, Lorestan University of Medical Sciences, Khorramabad, Iran \\ ${ }^{2}$ Infectious Diseases and Tropical Medicine Research Center, Isfahan University of Medical Sciences, Isfahan, Iran
}

\section{A R T I C L E I N F O}

Article Type:

Review

\section{Article History:}

Received: 7 April 2019

Accepted: 20 July 2019

Published online: 21 August 2019

Keywords:

Helicobacter pylori

Magnesium

Hypomagnesaemia

Renal disease

\begin{abstract}
A B S T R A C T
One of the problems of renal disease patients, especially patients undergoing dialysis, is gastrointestinal complications caused by Helicobacter pylori infection. H. pylori has still high prevalence in most populations. It is estimated that about half of the world population is infected with this infection and it can change levels of most micronutrients such as magnesium. Different studies demonstrate that $H$. pylori may affect the metabolism of magnesium in renal failure. The present paper investigated the association of serum magnesium level with $H$. pylori infection. Nevertheless, it should be more evaluated by researchers and still many studies are necessary to confirm this issue.
\end{abstract}

Implication for health policy/practice/research/medical education:

The present study investigated the association of serum magnesium level with $H$. pylori infection. The result of the review revealed the association between serum magnesium level and $H$. pylori infection in renal disease patients. However, it should be more analyzed by researchers and many studies are necessary to confirm this issue.

Please cite this paper as: Yalameha B, Nasri P. Helicobacter pylori infection and serum magnesium in kidney disease; current concepts. J Nephropharmacol. 2020;9(1):e11. DOI: 10.15171/npj.2020.11.

\section{Introduction}

Helicobacter pylori is a spiral, highly mobile, gramnegative, and urease-positive bacterium that involves gastric mucosa. Several studies suggest that the bacterium may be one of the microorganisms that cause numerous complications and consequences. One of the most abundant infections is gastrointestinal infection in most people (more than $80 \%$ ) $(1,2)$. Considering specific morphology and very fast growth of $H$. pylori, it penetrates into the viscous mucus layer through $\mathrm{pH}$ neutral conditions (Figure 1) (3). It can be inactive in difficult conditions. Various enzymes of $H$. pylori such as protease produce a high amount of osmosis that modifies the gastric mucosa and reduces the ability of acid to release more in the mucus (4). H. pylori infection is transmitted through various ways. Data from recent research show that transmission of infection is through consumption of contaminated water and food, interpersonal, contact with the stool or stomach secretion of infected people and even parental. The risk of infection is higher in populated societies, poor people, and low health conditions, therefore sanitation is the effective factor in preventing the infection (1). H. pylori infection is a main pathogenetic factor for gastric cancer, peptic ulcer disease, chronic gastritis, and other disorders. The infection can alter the homeostasis of minerals and vitamins. It is known that $H$. pylori infection has a direct relationship with the reduction of levels of several micronutrients like cobalamin, vitamin A, C, $\mathrm{E}$ and B12, copper, and folic acid (4-6). In addition, the infection leads to iron-deficiency anemia through iron consumption, decreasing ascorbic acid level, and bleeding due to micro-erosions (7). Recently, multiple studies have been indicated an association between $H$. pylori infection and serum magnesium in renal disease patients that the present study addresses this issue.

\section{Materials and Methods}

In the review, we used a variety of sources including, 


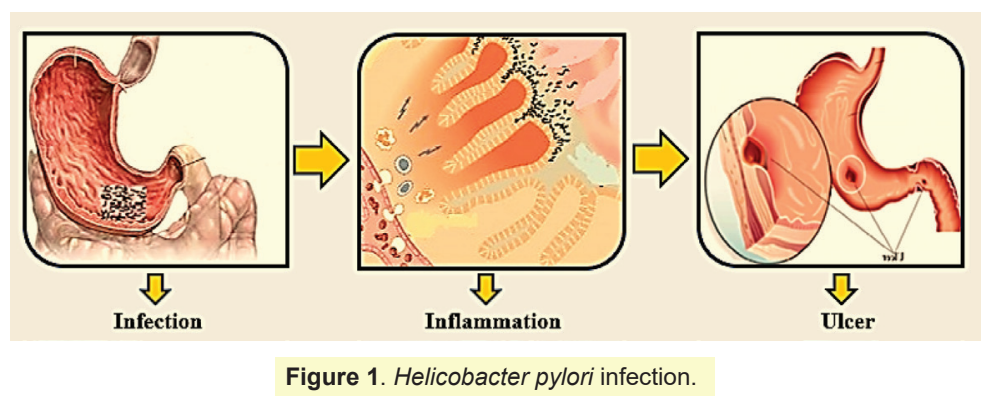

PubMed/Medline, Google Scholar, Science Direct, Web of Science, Embase, EBSCO, Directory of Open Access Journals (DOAJ), and Scopus. The search was performed by using combinations of the keywords; Helicobacter pylori infection, serum magnesium, hypomagnesemia, renal disorders, hemodialysis, proton-pump inhibitors, nephrotoxicity, chronic kidney disease, end-stage renal disease, and renal disease patients.

\section{Magnesium level in different diseases}

Magnesium, as an intracellular cation and cofactor for over 900 enzymes, involves in important cellular processes, such as energy production, DNA transcription, DNA structure maintenance, regulation of cell proliferation, differentiation, apoptosis, and bone metabolism. The ion affects the function of muscles, blood vessels, bones, nervous system, pancreas, and kidneys (8-10). The normal range of serum magnesium concentration is 1.8 to $2.4 \mathrm{mEq} / \mathrm{L}$. Magnesium is mainly found in legumes, nuts, green vegetables, seeds, and even water. Therefore, the consumption of a diet of magnesium-rich will help to meet the daily requirement of magnesium (11). In general, the average daily intake of magnesium in a healthy person is $12 \mathrm{mmol} /$ day. About $2 \mathrm{mmol} / \mathrm{day}$ of magnesium is excreted in the gastrointestinal tract, bile, pancreas and intestinal juices (12). Details of magnesium metabolism have been demonstrated in Figure 2. The different factors such as storage in skeletal muscle and bone, intestinal uptake, and renal excretion play a vital role in magnesium balance. Serum level less than 1.5 $\mathrm{mEq} / \mathrm{L}$ is called hypomagnesemia. Hypomagnesemia is related to malnutrition, alcoholism, malabsorption, and renal disease (11). It may occur by numerous medications including proton-pump inhibitors (PPIs), aminoglycoside antibiotics, cisplatin, thiazide diuretics (13). The relationship between low-level of magnesium and the prevalence of diseases as atherosclerosis, insulin resistance, type 2 diabetes, high blood pressure, and cardiovascular disease has been proven. However, hypomagnesemia accelerates immune stress response in the animal model (14). Low-serum magnesium increased the mortality rate in patients with cardiovascular disease and accelerated subclinical atherosclerosis by enhancing artery intima thickness. Although this relationship requires more research in the future (15). Serum level higher than 2.5 $\mathrm{mEq} / \mathrm{L}$ is called hypermagnesemia. Hypermagnesemia is less common and can be the result of the excessive intake of magnesium, renal failure, depression, milk-alkali syndrome, and Addison's disease (12). Magnesium, as a cofactor, interferes with glucose metabolism and plays a main role in phosphorylation reactions. Hypomagnesemia has no positive effect on impairing insulin-mediated glucose uptake, glucose-induced insulin secretion, and post-receptor signaling of insulin. Magnesium can regulate

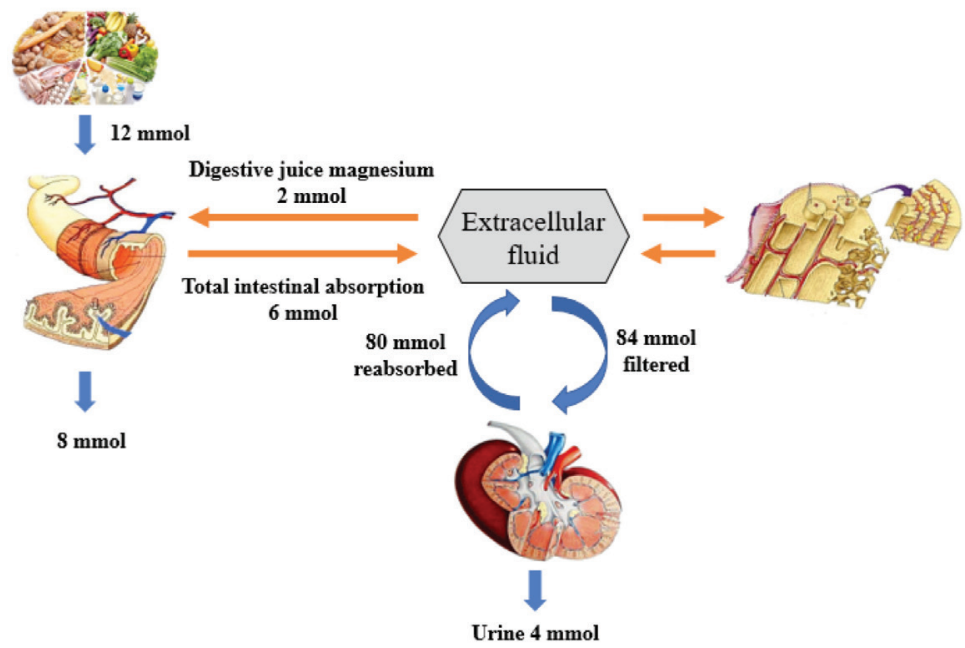

Figure 2. Magnesium distribution in the body. 
lipid metabolism and affect lipid parameters like LDLcholesterol, HDL-cholesterol, serum total cholesterol, and triglyceride. It has been suggested a kind of relationship between hypomagnesemia and lipid parameters (16). Nasri et al in a cross-sectional study evaluated serum creatinine, cholesterol, HDL-C, triglyceride, serum lipoprotein (a), glycosylated hemoglobin (HgbA1c), and serum magnesium to detect the correlation between serum magnesium and lipids profile in diabetes mellitus patients. This study was done on 122 patients with mean age 63 years. According to the results of this study, the mean serum magnesium level and creatinine clearance were $2 \mathrm{mg} / \mathrm{dL}$ and $64 \mathrm{cc} / \mathrm{min}$, respectively. In this study, a significant reverse relationship was observed between serum magnesium level and serum LDL-C, serum cholesterol, and also with age of patients. Furthermore, a positive correlation of serum magnesium with serum creatinine was confirmed. Although, there was no significant association between serum magnesium level and HDL-cholesterol, triglyceride, serum lipoprotein (a), albumin, and serum HgbA1c (17).

One of the most effective medicines utilizable to contrast with different types of cancers, such as ovarian, bladder, head and neck cancer is cisplatin. Long-term use of this drug may lead to ototoxicity, myelosuppression, and especially nephrotoxicity. The complications of the use of this medication are renal tubule dysfunction, reduced glomerular filtration rate, and acute or chronic kidney failure. Cisplatin induces hypomagnesemia in treated head and neck cancer patients which eventually contribute to nephrotoxicity. A study was conducted to evaluate the effect of magnesium supplements on cisplatin-induced nephrotoxicity in cisplatin-treated head and neck cancer patients. The results of this study demonstrated that reduced creatinine clearance in the magnesium-supplemented and crystalloid-only (after two courses) groups was $4.9 \mathrm{~mL} / \mathrm{kg} / \mathrm{min}$ and $15.0 \mathrm{~mL} / \mathrm{kg} /$ min respectively and magnesium-supplemented regimen inhibits cisplatin-induced nephrotoxicity in head and neck cancer patients (18).

\section{Magnesium level in renal disease patients}

Kidney disorders are recognized as one of the prevalent diseases in the general population, thus the treatment and prevention of them have significant clinical importance. Several factors are involved in causing renal failure including side effects of some medications (19). The kidneys have an essential role in maintaining magnesium balance (12). Magnesium homeostasis can change in renal disease especially chronic kidney disease (CKD) and end-stage renal disease (ESRD) (13). Additionally, it is identified that serum magnesium level alters in patients with ESRD undergoing dialysis, acute renal failure, continuous ambulatory peripheral dialysis, and rhabdomyolysis. Some studies suggested that urinary excretion of magnesium may reduce in stone formers which can help to the pathogenesis of renal calculi (12).

It is reported that low-serum magnesium leads to high cardiovascular mortality and increases the progression of kidney disorders in 191 diabetics with CKD (20). In addition to the mentioned studies, Parvizi et al demonstrated that magnesium has a protective effect on renal function in diabetic rats. Magnesium sulfate administration decreased creatinine, serum BUN, and blood glucose and also improved oxidative damages and renal disorder (21).

Lipid disorders are one of the serious problems of population since kidney dysfunction is a known factor in the occurrence of this disorder. Dyslipidemia is recognized as a major cause of atherosclerosis progression in hemodialysis patients. A study was carried out on 36 hemodialysis patients to show the correlation of serum magnesium with factors involved in the progression of dyslipidemia in hemodialysis patients including triglyceride, HDL-C, LDL-C, cholesterol, serum lipoprotein (a), intact parathyroid hormone (PTH), magnesium, phosphorus, and calcium. At the end of the study, there was no relationship between intact PTH, serum calcium, and $\mathrm{Ca} \times \mathrm{P}$ product with lipids levels. However, a positive relation was identified between serum magnesium with triglyceride level and lipoprotein (a). Additionally, magnesium could modify enzymes involved in lipoprotein synthesis and triglyceride metabolism (22).

Proton- pump inhibitors (PPIs) are one of the most common treatments for all diseases associated with gastric acid. Recently, there are reports of hypomagnesemia caused by the consumption of PPIs, which are often due to reduced magnesium gastrointestinal reabsorption. Although, the prevalence of hypomagnesemia following PPIs intake is still unclear. PPIs may alter serum magnesium level in hemodialysis patients that many studies should be conducted to clarify the association between PPIs and magnesium levels in these patients. About this issue, Nakashima et al conducted a study on 1189 hemodialysis patients. Biochemical factors such as albumin, creatinine, alkaline phosphatase, potassium, magnesium, calcium, phosphorus, blood urea nitrogen, hemoglobin, C-reactive protein, and intact PTH were measured. The results showed that 104 of the 1189 HD patients have hypomagnesemia. The mean serum magnesium levels were significantly less in PPI consumers group than $\mathrm{H} 2$ receptor antagonists consumers group or patients receiving no anti-acid drugs (23).

Erectile dysfunction is the prevalence among elderly patients. It has been suggested that hypomagnesemia affects erectile dysfunction in the elderly with CKD. Toprak et al evaluated the relationship between erectile dysfunction and hypomagnesemia in a cross-sectional study on of 372 patients with CKD aged 65-85 years and reported that erectile dysfunction causes hypomagnesemia in elderly patients with reduced kidney function (24).

A different study on gene mutations effect and 
magnesium level identified that mutations in tightjunction gene claudin 19 (CLDN19) affected magnesium homeostasis and high expression of CLDN19 induces excretion of renal magnesium in patients with renal failure (25).

The relation of Helicobacter pylori infection with serum magnesium level in renal disease patients

Helicobacter pylori infection can alter the metabolism of some mineral and trace elements including magnesium in children and the lack of micronutrients induces the progression of many diseases (5). One of the causes of the presence of gastrointestinal complications in patients on hemodialysis is $H$. pylori infection. However, more the occurrence of the infection in these people is still unclear and it may be interpreted as being a result of urea concentration in gastric secretion or uremia which facilitates incidence of infection (26). Magnesium is an important mineral that participates in the reaction and process of the human body. Different evidence suggests that $H$. pylori infection can alter the level of magnesium in renal disease patients. For example, a survey of 44 hemodialysis patients, including 34 nondiabetics and 10 diabetics with ESRD illustrated a significant relationship between magnesium level and $H$. pylori. It has been exhibited that, high plasma level of magnesium leading to increased $H$. pylori activity in hemodialysis patients (27). Additionally, a study in 2005 reported the correlation between $H$. pylori-specific IgG antibody titers and magnesium levels in the stomachs of 44 hemodialysis patients (10 diabetics and 34 nondiabetics). The result of this study was revealed that colonization of $H$ pylori may result from the higher concentration of magnesium in the gastric mucosa (28). Hafizi et al evaluated the association between serum magnesium and H. pylori infection in 50 patients with kidney transplant and reported that serum magnesium was more in positive $H$. pylori patients than negative $H$. pylori patients. No significant difference observed in serum alkaline phosphatase, intact PTH, calcium, albumin, and even body mass index (BMI) between men and women (29). The findings of another study in 94 patients with type-2 diabetes mellitus with different glomerular function rates (GFRs) was in contrast with previous evidence. In this study, no significant difference detected between serum magnesium and $H$. pylori infection among T2DM patients with GFR below 40 $\mathrm{mL} / \mathrm{min}(30)$. The results of study conducted by Baradaran et al on the relationship between different demographic and biochemical parameters and serum $H$. pylori IgG antibody titers in 72 renal transplants patients, (consisted of 47 males and 25 females) showed no significant association between $H$. pylori IgG antibody titers and magnesium, calcium, intact PTH, albumin, alkaline phosphatase levels, phosphorus, serum leptin, BMI, and age in women and men. In addition, a significant negative correlation was reported between serum $H$. pylori IgG Ab titer and magnesium and intact PTH while the correlation between $H$. pylori IgG Ab titer and creatinine clearance was significantly positive (31). Hyperhomocysteinemia is a main risk factor for atherosclerosis and related to changes in vascular morphology, loss of vessels endothelial function that activates the pathway of coagulation and formation of thrombosis (32). A study carried out on 39 patients under hemodialysis revealed that $H$. pylori infection can affect serum homocysteine in hemodialysis patients, although is suggested more research on this association (33). A recent study of the literature on this matter in an animal model found that the combination of bismuth and magnesium granules can clear $H$. pylori infection in $\mathrm{KM}$ mice by inhibition of associated inflammation factors such as IL-8 and TNF- $\alpha$. on the other hand, H. pylori clearance rates in compound bismuth and magnesium granules group was $60.0 \%$. Additionally, the compound improved gastric mucosal injury due to $H$. pylori infection (34). Savas et al conducted a study on 64 endoscopic findings of renal transplanted patients and investigated the prevalence of $H$. pylori infection was less in chronic renal failure patients than in the normal people since agents other than $H$. pylori involved in the occurrence of esophagogastroduedenal mucosal lesions (35). Rasmi et al surveyed the role of duration $\mathrm{HD}$ on the prevalence of $H$. pylori infection and concluded that the prevalence of the infection is higher in patients on long-term HD duration (26). A cross-sectional study conducted on 40 ESRD undergoing peritoneal dialysis patients including 18 males and 22 females with a range of age 16-80. Patients were dialyzed for at least 6 months and then analyzed for biochemical factors such as albumin, creatinine, serum urea, calcium, phosphorus, magnesium, 25-hydroxyvitamin D, PTH, and serum $H$. pylori specific IgG antibody. Antibody titer was positive in $45 \%$ of patients. No significant difference appeared between magnesium level and $H$. pylori specific IgG antibody. Although the positive relationship serum magnesium with serum creatinine levels was quite evident, there was no association between $H$. pylori specific IgG $\mathrm{Ab}$ titer and albumin, creatinine, serum urea, calcium, phosphorus, magnesium, 25-hydroxyvitamin D, PTH, and age (36).

\section{Conclusion}

Recent studies suggest that the prevalence of $\mathrm{H}$. pylori is still evident in most countries and many people are affected by this infection. The result of the review revealed the association between serum magnesium level and $\mathrm{H}$. pylori infection in renal disease patients. However, it should be more analyzed by researchers and many studies are necessary to confirm this issue.

Authors' contribution

BY prepared the primary draft and conducted search 
strategy. PN edited the paper. All authors read and signed the final paper.

\section{Conflicts of interest}

The authors declare that they have no competing interest.

\section{Ethical considerations}

Ethical issues (including plagiarism, misconduct, data fabrication, falsification, double publication or submission, redundancy) have been completely observed by the authors.

\section{Funding/Support}

None.

\section{References}

1. Logan RP, Walker MM. ABC of the upper gastrointestinal tract: epidemiology and diagnosis of Helicobacter pylori infection. BMJ. 2001;323:920-2.

2. Ortiz D, Cavazza ME, Rodríguez O, Hagel I, Correnti M, Convit J. Prevalence of Helicobacter pylori infection in Warao lineage communities of Delta Amacuro State, Venezuela. Mem Inst Oswaldo Cruz. 2003;98:721-5.

3. Kusters JG, van Vliet AHM, Kuipers EJ. Pathogenesis of Helicobacter pylori Infection. Clin Microbiol Rev. 2006;19:449-90. doi: 10.1128/CMR.00054-05.

4. Hussain SA, Hamid S. Helicobacter pylori in humans: Where are we now? Adv Biomed Res. 2014;3:63. doi: 10.4103/2277-9175.125844.

5. Öztürk N, Kurt N, Özgeriş FB, Baygutalp NK, Tosun MS, Bakan N, et al. Serum zinc, copper, magnesium and selenium levels in children with Helicobacter pylori infection. Eurasian J Med. 2015;47:126-9. doi: 10.5152/ eurasianjmed.2015.104.

6. Lahner E, Persechino S, Annibale B. Micronutrients (Other than iron) and Helicobacter pylori infection: a systematic review. Helicobacter. 2012;17:1-15. doi: 10.1111/j.15235378.2011.00892.x.

7. Camaschella C. Iron-deficiency anemia. N Engl J Med. 2015;372:1832-43. doi: 10.1056/NEJMra1401038.

8. Sherer Y, Shaish A, Levkovitz H, Keren P, Janackovic Z, Shoenfeld Y, et al. Magnesium fortification of drinking water suppresses atherogenesis in male LDL-receptordeficient mice. Pathobiology. 1999;67:207-13. doi: $10.1159 / 000028074$

9. Wang JZ. Determination of intraerythrocytic $\mathrm{Na}+, \mathrm{K}+$, $\mathrm{Ca}++, \mathrm{Mg}++$ and cell-membrane $\mathrm{Na}+\mathrm{K}+$-ATPase activities: its diagnostic value in digoxin poisoning. Zhonghua Yi Xue Za Zhi. 1987;67:366-8.

10. Hartwig A. Role of magnesium in genomic stability. Mutat Res. 2001;475:113-21.

11. Mathers TW, Beckstrand RL. Oral magnesium supplementation in adults with coronary heart disease or coronary heart disease risk. J Am Acad Nurse Pract. 2009;21:651-7. doi: 10.1111/j.1745-7599.2009.00460.x.

12. Swaminathan R. Magnesium metabolism and its disorders. Clin Biochem Rev. 2003;24:47-66.

13. van de Wal-Visscher ER, Kooman JP, van der Sande FM.
Magnesium in chronic kidney disease: should we care? Blood Purif. 2018;45:173-8. doi: 10.1159/000485212.

14. Guerrero-Romero F, Rodríguez-Morán M. Relationship between serum magnesium levels and C-reactive protein concentration, in non-diabetic, non-hypertensive obese subjects. Int J Obes Relat Metab Disord. 2002;26:469-74.

15. Kieboom BC, Niemeijer MN, Leening MJ, van den Berg ME, Franco OH, Deckers JW, et al. Serum magnesium and the risk of death from coronary heart disease and sudden cardiac death. J Am Heart Assoc. 2016;5:e002707. doi: 10.1161/JAHA.115.002707.

16. Bo S, Pisu E. Role of dietary magnesium in cardiovascular disease prevention, insulin sensitivity and diabetes. Curr Opin Lipidol. 2008;19:50-6. doi: 10.1097/ MOL.0b013e3282f33ccc.

17. Nasri H, Baradaran HR. Lipids in association with serum magnesium in diabetes mellitus patients. Bratisl Lek Listy. 2008;109:302-6.

18. Kimura T, Ozawa T, Hanai N, Hirakawa H, Suzuki H, Hosoi $\mathrm{H}$. Renal protective effect of a hydration supplemented with magnesium in patients receiving cisplatin for head and neck cancer. J Otolaryngol Head Neck Surg. 2018;47:10. doi: 10.1186/s40463-018-0261-3.

19. Ghane Shahrbaf F, Assadi F. Drug-induced renal disorders. J Renal Inj Prev. 2015;4:57-60.

20. Floege J. Magnesium in CKD: more than a calcification inhibitor? J Nephrol. 2015;28:269-77. doi: 10.1007/s40620014-0140-6.

21. Parvizi MR, Parviz M, Tavangar SM, Soltani N, Kadkhodaee M, Seifi B, et al. Protective effect of magnesium on renal function in STZ-induced diabetic rats. J Diabetes Metab Disord. 2014;13:84. doi: 10.1186/s40200-014-0084-3.

22. Nasri $\mathrm{H}$, Baradaran A. Correlation of serum magnesium with dyslipidemia in maintenance hemodialysis patients. Acta Medica (Hradec Kralove). 2004;47:263-5.

23. Nakashima A, Ohkido I, Yokoyama K, Mafune A, Urashima $\mathrm{M}$, Yokoo T. Proton pump inhibitor use and magnesium concentrations in hemodialysis patients: a cross-sectional study. PLoS One. 2015;10:e0143656. doi: 10.1371/journal. pone.0143656.

24. Toprak O, Sarı Y, Koç A, Sarı E, Kırık A. The impact of hypomagnesemia on erectile dysfunction in elderly, nondiabetic, stage 3 and 4 chronic kidney disease patients: a prospective cross-sectional study. Clin Interv Aging. 2017;12:437-44. doi: 10.2147/CIA.S129377.

25. Konrad M, Schaller A, Seelow D, Pandey AV, Waldegger $\mathrm{S}$, Lesslauer A, et al. Mutations in the tight-junction gene claudin 19 (CLDN19) are associated with renal magnesium wasting, renal failure, and severe ocular involvement. Am J Hum Genet. 2006;79:949-57.

26. Rasmi Y, Farshid S, Makhdomi K. Effect of duration on hemodialysis on prevalence of Helicobacter pylori infection. Saudi J Kidney Dis Transpl. 2012;23:489-92.

27. Nasri H. Helicobacter pylori infection and its relationship to plasma magnesium in hemodialysis patients. Bratisl Lek Listy. 2007;108:506-9.

28. Nasri H, Baradaran A. Relationship of Helicobacter pylori specific IgG antibodies with serum magnesium in patients on maintenance hemodialysis. J Appl Res. 2005;5:438-443.

29. Hafizi M, Mardani S, Borhani A, Ahmadi A, Nasri P, Nasri 
H. Association of Helicobacter pylori infection with serum magnesium in kidney transplant patients. J Renal Inj Prev. 2014;3:101-5. doi: 10.12861/jrip.2014.29.

30. Baradaran A, Nasri H. Helicobacter pylori specific IgG antibody and serum magnesium in type-2 diabetes mellitus chronic kidney disease patients. Saudi J Kidney Dis Transpl. 2011;22:282-5.

31. Baradaran A, Nasri H. Association of Helicobacter pylori IgG antibody with various demographic and biochemical parameters in kidney transplant recipients. Saudi J Kidney Dis Transpl. 2011;22:1115-20.

32. McCully KS. Homocysteine and vascular disease. Nat Med. 1996;2:386-9.

33. Rafieian-Kopaei M, Baradaran A, Maghsoudi A, Ghobadi S, Nasri H. Helicobacter pylori infection and serum homocysteine in hemodialysis patient. Life Sci J.
2012;9:3696-702.

34. Mu FH, Hu FL, Wei H, Zhang YY, Yang GB, Lei XY, et al. Protective effect of compound bismuth and magnesium granules on aspirin-induced gastric mucosal injury in rats. Zhonghua Yi Xue Za Zhi. 2016;96:464-7. doi: 10.3760/cma. j.issn.0376-2491.2016.06.012.

35. SAVAŞ N. Helicobacter pylori prevalence and its association with endoscopic findings in renal transplant candidates. Candidates Akademik Gastroenteroloji Dergisi. 2014;13:7982.

36. Alirezaei A, Movassagh koolankuh S, Talaie R, Azmoodeh S, Bakhtiyari M. Association of Helicobacter pylori specific IgG antibody with serum magnesium levels in peritoneal dialysis patients. J Nephropharmacol. 2017;6:142-5. doi: 10.15171/npj.2017.22.

Copyright $\odot 2020$ The Author(s); Published by Published by Society of Diabetic Nephropathy Prevention. This is an open-access article distributed under the terms of the Creative Commons Attribution License (http://creativecommons.org/licenses/by/4.0), which permits unrestricted use, distribution, and reproduction in any medium, provided the original work is properly cited. 